


\title{
Immunofluorescence in Oral Pathology-Part III: Pathology and Immunofluorescent Patterns in Intraepithelial Immunobullous Disorders
}

\author{
Roopa S Rao, BR Premalatha, Vijaya Mysorekar, Saurabh Juneja
}

\begin{abstract}
Dermatologic disorders frequently parallel with oral involvement which dental practitioners should be familiar with. In continuation with part II, the immunofluorescence patterns in the intraepidermal pemphigus group and its variants: Pemphigus vulgaris (PV) and paraneoplastic pemphigus (PNP) are dealt in this section. Also, a brief note is added on other mucocutaneous disorders showing similar immunofluorescence patterns. The above listed immunobullous disorders are reviewed in detail with a summary of pathogenesis and characteristic histopathological findings. This review is to facilitate the clinicopathologist in the early diagnosis and subsequent treatment of these debilitating conditions.
\end{abstract}

Keywords: Intraepidermal immunobullous diseases, Immunofluorescence patterns, Oral mucosa.

How to cite this article: Rao RS, Premalatha BR, Mysorekar V, Juneja S. Immunofluorescence in Oral Pathology-Part III: Pathology and Immunofluorescent Patterns in Intraepithelial Immunobullous Disorders. World J Dent 2012;3(2):202-206.

\section{Source of support: Nil}

Conflict of interest: None declared

\section{INTRODUCTION}

Immunobullous diseases constitute an important group of dermatological disorders caused by autoantibodies directed against antigens in the intercellular substance or dermoepidermal/epithelial junction resulting in the formation of cutaneous and mucosal blisters. ${ }^{1}$ Immunobullous diseases with oral mucosal involvement can be divided into intraepithelial/intraepidermal and subepithelial/subepidermal. The intraepithelial diseases include the pemphigus group and its variants: Pemphigus vulgaris (PV), pemphigus foliaceus (PF), etc. The subepithelial immunobullous group of lesions was discussed in detail in part II of this series. The intraepidermal immunobullous disorders and other mucocutaneous disorders sharing similar immunofluorescence patterns namely lichen planus (LP), systemic lupus erythematosus (SLE), discoid lupus erythematosus (DLE) and erythema multiforme (EM) are dealt in this section.

\section{PEMPHIGUS GROUP OF LESIONS}

It includes a group of chronic mucocutaneous, autoimmune blistering diseases that develop in cycles characterized by intraepithelial blisters histologically, and immunologically, circulating $\operatorname{IgG}$ directed against the cell surface of keratinocytes. Pemphigus can be classified into 6 types: pemphigus vulgaris $(\mathrm{PV})$, pemphigus vegetans, pemphigus erythematosus, pemphigus foliaceus (PF), paraneoplastic pemphigus (PNP), and immunoglobulin IgA pemphigus. ${ }^{2,3}$ Pemphigus vulgaris is the main variant followed by PNP that usually affects the mouth and precedes skin lesions in most $_{\text {cases. }}{ }^{3}$

\section{PEMPHIGUS VULGARIS}

Pemphigus vulgaris is an autoimmune mucocutaneous disorder mediated by circulating autoantibodies directed against keratinocyte cell surfaces. Oral lesions are seen in $90 \%$ of patients, usually at an early stage and can precede cutaneous lesions in weeks, months or more than 1 year.

\section{Histopathology}

The histopathological features of PV reflect the action of the circulating antibody on the cell surface of the prickle cells and consequent destruction of the desmosomes termed as acantholysis. This results in the formation of clefts and then blisters or bullae in a predominantly suprabasal location $^{4-8}$ (Fig. 1). The acantholytic cells called Tzanck cells are found in the vesicular space (Fig. 2). Sometimes the entire superficial layers of the epithelium are stripped away, leaving only the basal cells forming a 'row of tomb stones' as the basal cells are firmly attached to the basement membrane by hemidesmosomes ${ }^{5,6,8}$ (Fig. 3).

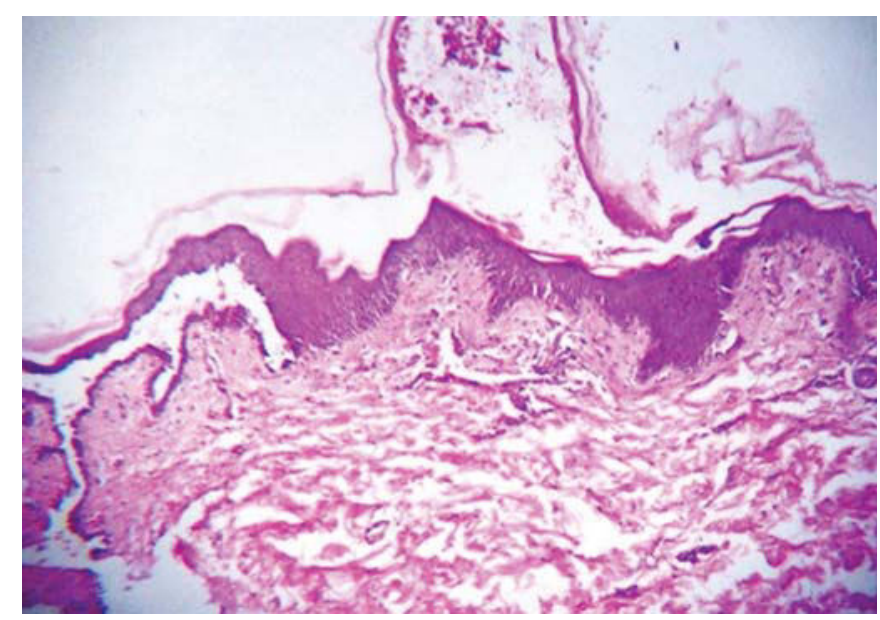

Fig. 1: Pemphigus vulgaris: $H$ and $E$ stained section at $4 \times$ showing a suprabasal blister 


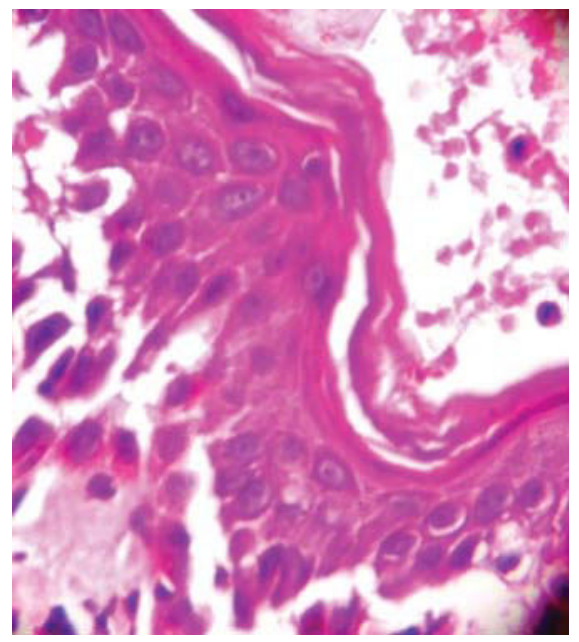

Fig. 2: Pemphigus vulgaris: $\mathrm{H}$ and $\mathrm{E}$ stained section at $40 \times$ showing acantholytic cells in the suprabasal blister

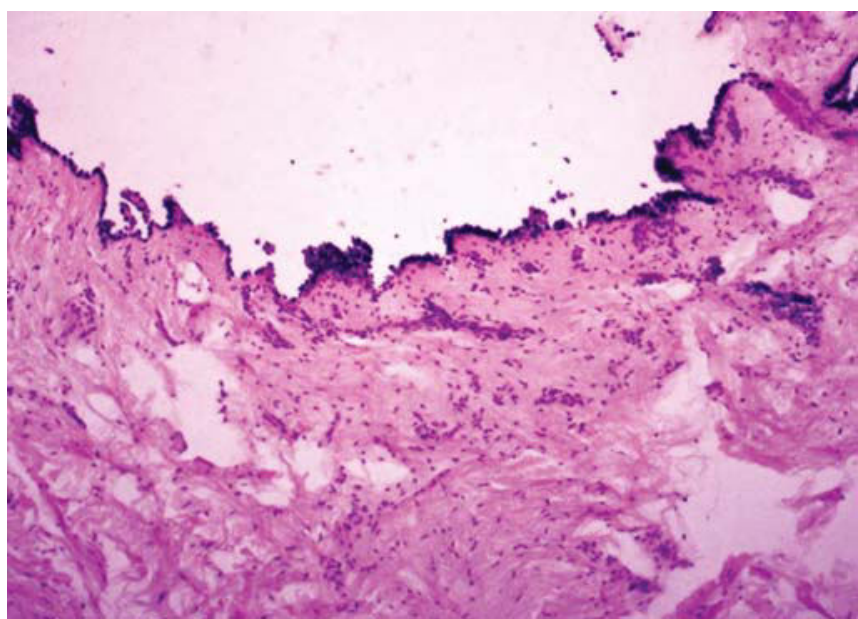

Fig. 3: Pemphigus vulgaris: $H$ and $E$ stained section at $10 x$ showing dermal papillae (villi) lined by a single layer of preserved basal keratinocytes presenting a 'row of tomestones' appearance

A feature that is often helpful diagnostically is the villous projections that may develop at the base of the bulla. When the surface epithelium ultimately separates, the mucosa will appear to have a surface of papillary projections lined by basal cells with some acantholytic cells. Once the bulla ruptures, the underlying connective tissue becomes highly inflammed. The eosinophilic infiltrate often seen in skin occurs infrequently in oral mucosa. ${ }^{9}$

\section{Pathogenesis}

The etiology and pathogenesis of PV are not completely clear. Compelling evidence has accumulated that IgG serum autoantibodies are directed against a cadherin-type cell adhesion molecule in stratified squamous epithelia, called desmoglein 3 and $1 .{ }^{10}$ In PV IgG antibodies are directed particularly to desmoglein 3 , and since oral epithelium

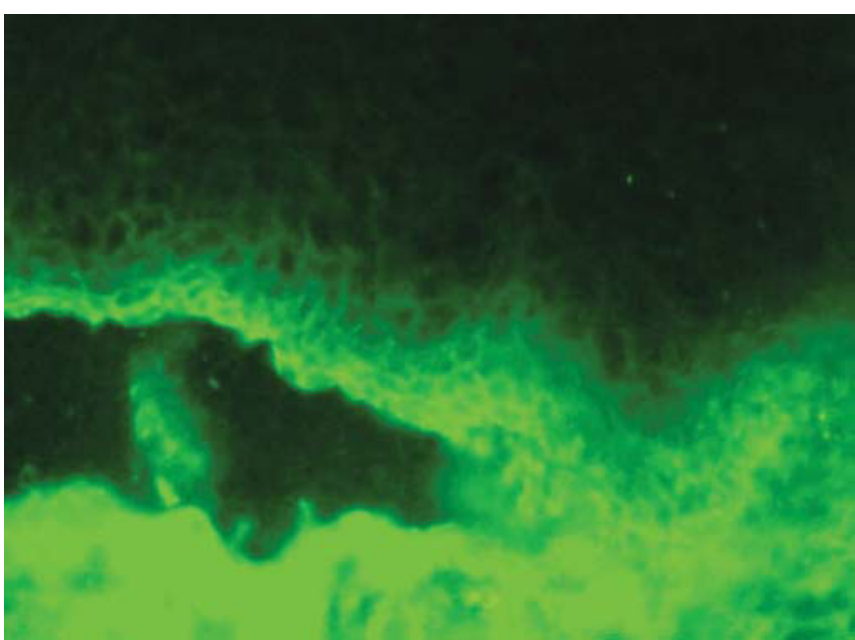

Fig. 4: Pemphigus vulgaris: Direct immunofluorescence showing the suprabasal cleavage. Lace-like deposition of $\lg G$ is seen in the squamous intercellular spaces in the lower epidermis (Courtesy: Dr HC Mahadeva and Dr Arundati)

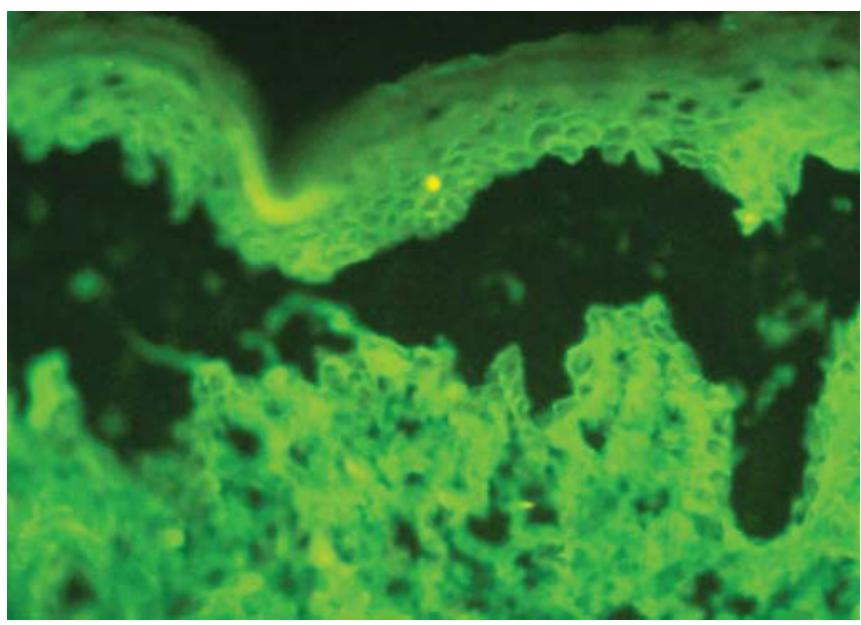

Fig. 5: Pemphigus vulgaris: Direct immunofluorescence showing the suprabasal cleavage. Lace-like deposition of C3 is seen in the squamous intercellular spaces in the lower epidermis (Courtesy: Dr HC Mahadeva and Dr Arundati)

expresses largely desmoglein 3, oral lesions appear at an early stage. The presence of antibodies against desmoglein 1 (found in over $50 \%$ of cases) may result in cutaneous involvement. Damage to the intercellular area between keratinocytes leads to apoptosis resulting in separation of the keratinocytes, acantholysis (cleavage) and then blistering. ${ }^{10}$ This occurs mostly at the level just superficial to basal cells. ${ }^{5}$ Antibody binding may activate complement with release of inflammatory mediators and recruitment of activated T cells. ${ }^{11}$

\section{Immunofluorescent Patterns and its Significance}

Direct immunofluorescence (DIF) testing is a very reliable and sensitive diagnostic test for pemphigus vulgaris. IgG or IgM and $\mathrm{C} 3$ expression are present in the squamous intercellular/cell surface areas in up to $95 \%$ of cases, including early cases and those with very few lesions. 
Intercellular expression of $\mathrm{IgG}$ or IgM and $\mathrm{C} 3$ are present in up to $100 \%$ of cases with active disease. ${ }^{12} \mathrm{IgG}$ deposits are greater than IgM, IgA and C3. Fluorescence of greatest intensity is seen in the parabasal region. Chicken wire/ fishnet pattern of deposition is noted around spinous cells of the epithelium in intercellular spaces. ${ }^{1,5,11}$ Complement component $\mathrm{C} 3$ may be seen in a pattern similar to that of $\mathrm{IgG}$, but with lower frequency and intensity. However, the diagnosis of pemphigus should not be made when only $\mathrm{C} 3$ is deposited ${ }^{1}$ (Figs 4 and 5).

Direct immunofluorescence (DIF) may be used to assess disease activity during therapy-induced remission. Negative DIF findings may be a good prognostic indicator when the patient is in remission. ${ }^{13}$

Indirect immunofluorescence (IIF) studies during active disease reveal an IgG antibody to the intercellular cement substance of stratified cornified epithelium in almost $90 \%$ of cases. ${ }^{14}$ The calcium enhancement technique will enhance detection of these antibodies whose titer reflects disease activity. ${ }^{15,16} \mathrm{~A}$ two-fold or greater increase in the titer suggests impending relapse. ${ }^{17}$ The absolute titer may be a poorer predictor of clinical status than the trend over some time although very high or absent levels usually correlate with active or inactive disease respectively. ${ }^{18}$ Antibodies are predominantly IgG4 subclass. ${ }^{19}$

\section{PARANEOPLASTIC PEMPHIGUS}

Paraneoplastic pemphigus (PNP) is a specific paraneoplastic disorder most commonly associated with lymphomas. ${ }^{20}$ Oral mucosal involvement is the earliest feature of PNP.

Histopathology: Histology shows suprabasal acantholytic separation, satellite keratinocyte necrosis, basal cell vacuolation, spongiosis and a lymphoid infiltrate at the epithelial-connective tissue interface. , $^{9,22}$

\section{Pathogenesis}

Patients with PNP develop IgG autoantibodies against multiple antigens. Mainly members of the plakin family, as well as desmogleins, are targeted by IgG autoantibodies in PNP. Antidesmoglein antibodies play a role in inducing the loss of cellular adhesion of keratinocytes and blister formation. The intracellular location of plakin proteins makes them unlikely initial targets. The damage to cell membranes induced by antidesmoglein IgG provides access into the cell for antiplakin autoantibodies; the latter then bind to their target antigens, inhibit their functions, and perhaps precipitate some unique features of PNP, such as dyskeratosis. ${ }^{23}$ In addition to the humoral autoimmunity, autoreactive cellular responses mediated by CD8+ cytotoxic T-lymphocytes, natural killer cells, and monocytes/ macrophages appear to be important in the pathogenesis of paraneoplastic autoimmune multiorgan syndrome. ${ }^{23}$

\section{Immunofluorescent Patterns and its Significance}

DIF studies may show weakly positive deposition of immunoreactants $\mathrm{IgG}$ and $\mathrm{C} 3$ almost invariably in the intercellular substance in perilesional skin and mucosa. ${ }^{20-22}$ C3, IgG and IgM may also be deposited along the basement membrane zone. ${ }^{20,22}$ However, false-negative DIF is more commonly noticed in PNP than in other forms of pemphigus. ${ }^{1,5,9,11}$

Indirect immunofluorescence testing using rat bladder transitional epithelium is highly specific for this disease. ${ }^{5,9,24,25}$ Circulating IgG anti-intercellular substance antibodies are almost always present in high titer. ${ }^{20}$

In pemphigus, titers of circulating intercellular antibodies can be correlated with disease activity; a twofold rise in titer may indicate an impending relapse. Of the four classes of $\mathrm{IgG}, \mathrm{IgG} 1$ is the best indicator of disease. ${ }^{26}$

Other dermatological conditions sharing similar immunofluorescence patterns like lichen planus (LP) systemic lupus erythematosus (SLE), discoid lupus erythematosus (DLE) and erythema multiforme (EM) are discussed briefly in this section.

\section{LICHEN PLANUS}

\section{Immunofluorescent Patterns and its Significance}

Direct IF: The shaggy deposits react with anti-fibrinogen to exhibit intensely positive fluorescnece in the basement membrane zone. ${ }^{27}$ Occasionally there are granular deposits of IgM or linear deposits of $\mathrm{C} 3 .^{28}$ The colloid apoptotic cells can also be demonstrated. They typically stain for IgM, but staining with $\operatorname{IgG}, \operatorname{IgA}, \mathrm{C} 3$ and fibrin may also be seen. ${ }^{9}$

Indirect IF: Negative and can be used to demonstrate lichen planus specific antigen (LPSA), which is expressed in the stratum granulosum and stratum spinosum. LPSA is specific for lichen planus and is found in $80 \%$ of patients with and without oral lesions. ${ }^{26}$

\section{BULLOUS SYSTEMIC LUPUS ERYTHEMATOSUS}

\section{Immunofluorescent Patterns and its Significance}

Direct IF: IgG and $\mathrm{C} 3$ are deposited at the epidermal basement membrane zone. The pattern is linear, but sometimes may be 'shaggy' or 'granular band-like'. A linear rather than granular pattern along the $\mathrm{BMZ}$ is associated with the presence of higher titer of circulating auto- 
antibodies. ${ }^{29,30} \operatorname{IgM}$ and $\operatorname{Ig} \mathrm{A}$ are present in approximately 50 to $60 \%$ of cases respectively. In general, granular patterns $(60 \%)$ represent deposition of circulating immune complexes in situ or in situ binding of antigen and antibody in compartmentalized zones. Similar deposition of IgG, IgM or complement in the normal skin is known as positive lupus band test. $^{5}$

Bullous SLE is associated with a higher incidence of IgA deposition (76\%) than other forms of SLE (17\%) and this may also correlate with renal involvement. ${ }^{31} \mathrm{C} 3$ is usually deposited in lesional skin. ${ }^{30}$

\section{DISCOID LUPUS ERYTHEMATOSUS}

\section{Immunofluorescent Patterns}

Direct IF : It is similar to SLE; most cases will demonstrate a granular pattern of $\operatorname{IgG}, \operatorname{IgM}, \operatorname{IgA}, \mathrm{C} 3$ and fibrinogen in the basement membrane zone of involved mucosa or skin. ${ }^{9}$ But, Ig can never be demonstrated in the uninvolved skin and mucosa in DLE. ${ }^{11}$

\section{ERYTHEMA MULTIFORME}

\section{Immunofluorescent Patterns}

Direct IF : By DIF, the superficial vessels of the connective tissue are seen to contain IgM and C3 in their walls. At the dermal-epidermal junction, granular deposits of IgM, fibrinogen and C3 may be seen. Circulating immune complexes have also been found. ${ }^{9}$

Indirect immunofluorescence is negative for circulating antibodies.

\section{CONCLUSION}

The gist of the entire article regarding antibodies, target antigen, structural target and immunofluorescence pzatterns of pemphigus and its variants and other mucocutaneous disorders sharing similar immunofluorescent patterns has been summarized in Table 1.

\section{ACKNOWLEDGMENTS}

We personally thank Dr S Kumar, President, Gokula Education Foundation and Dr Saraswathi Rao, Dean and

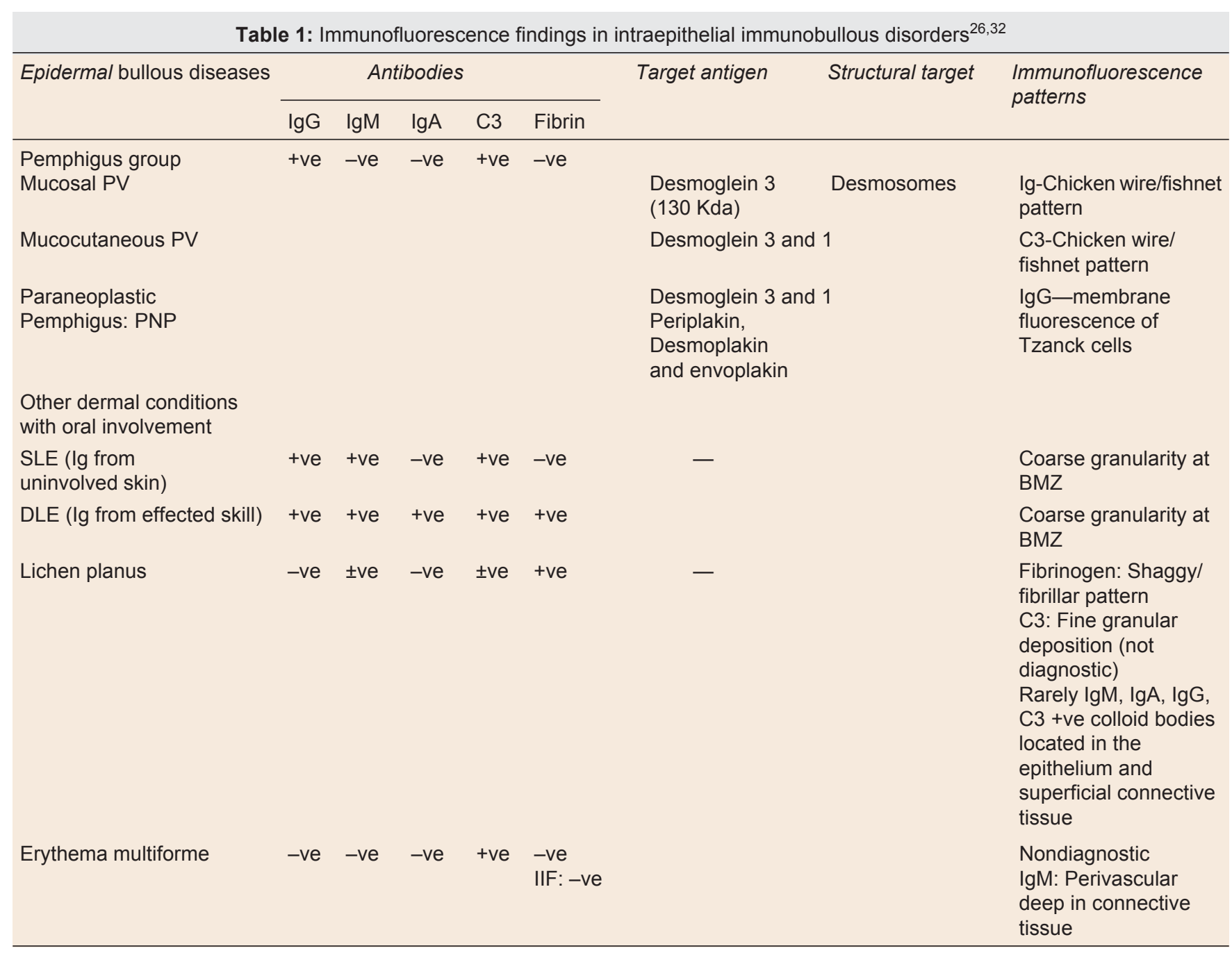


Principal of MS Ramaiah Medical College, Bengaluru for having permitted us to use the facilities available at MSRMC.

Photo courtesy: We are greatful to Dr KC Mahadeva, Professor and Head, Department of Pathology, MS Ramaiah Medical College and Dr Arundati, Tutor, Department of Pathology, MSRMC, Bangalore, for having helped us in procuring the photographs.

\section{REFERENCES}

1. Zahida Rani, Ijaz Hussain. Immunofluorescence in immunobullous diseases. Journal of Pakistan Association of Dermatologists 2003;13:76-882.

2. Hashimoto T. Recent advances in the study of the pathophysiology of pemphigus. Arch Dermatol Res 2003;295(Suppl 1): S2-11.

3. Robinson JC, Lozada-Nur F, Frieden I. Oral pemphigus vulgaris: A review of the literature and a report on the management of 12 cases. Oral Surg Oral Med Oral Pathol Oral Radiol Endod 1997;84:349-55

4. The vesiculobullous reaction pattern. In: Weedon D (Ed): Systemic Pathology. The Skin. (3rd ed). Edinburgh: ChurchillLivingstone 1992;9:127-80.

5. Oral and maxillofacial pathology. Neville Damm Allen Bonquot (2nd ed). WB Saunders Company 2002.

6. Lever WF. Pemphigus and pemphigoid. Springfield, IL: Charles C Thomas, 1965.

7. Tappeiner J, Pfleger L. Pemphigus vulgaris: Dermatitis herpetiformis. Arch Klin Exp Dermatol 1962;214:415.

8. Rajendran R, Sivapathasundaram B. Shafer's textbook of oral pathology (5th ed). Elsevier, 2006

9. Oral and maxillofacial pathology. Robert E Marx and Diane Stern, Quintessence Publishing Co, inc 2003;6.

10. Amagai M, Karpati S, Prussick R, et al. Autoantibodies against the amino- terminal cadherin-like binding domain of pemphigus vulgaris antigen are pathogenic. J CLI Invest 1992;90:919-26.

11. Cullings cellular pathology technique. CFA Cullings (4th ed), Butterworths 1984

12. Korman NJ, Pemphigus. J Am Acad Dermatol 1988;18:1219.

13. Ratnam KV, Pang BK. Pemphigus in remission: Value of negative direct immunofluorescence in management. J Am Acad Dermatol 1994;30:547.

14. Fellner MJ, Fukuyama K, Moshell A, Klaus MV. Intercellular antibodies in blood and epidermis. Br J Dermatol 1973;89: $115-26$.

15. Matis WL, Anhalt GJ, Diaz LA, et al. Calcium enhances the sensitivity of immunofluorescence for pemphigus antibodies. $\mathrm{J}$ Invest Dermatol 1987;89:302-04.

16. Creswell SN, Black MM, Bhogal B, Skeete MVH. Correlation of circulating intercellular antibody titers in pemphigus with disease activity . Clin Exp Dermatol 1981;6:477-83.

17. Beutner EH, Chorzelski TP, Jablonska S. Clinical significance of immunofluorescence test of sera and skin in bullous diseases: A cooperative study in immunopathology of the skin (3rd ed). New York: Jhon Wiley \& Sons Inc, 177-205.

18. Krasny SA, Beutner EH, Chrzelski TP. Specificity and sensitivity of indirect and direct immunofluorescent findings in the diagnosis of pemphigus in immunopathology of the skin (3rd ed). New York: Jhon Wiley \& Sons Inc, 1987;207-47.

19. Wilson CL, Wojnarowska F, Dean D, Pasricha JS. IgG subclasses in pemphigus in Indian and UK populations. Clin Exp Dermatol 1993;18:226-30.
20. Anhalt GJ, Kim S, Stanley JR, et al. Paraneoplastic pemphigus: An autoimmune mucocutaneous disease associated with neoplasia. N Eng J Med 1990;323:1729-35.

21. Horn TD, Analt GJ. Histologic features of paraneoplastic pemphigus. Arch Dermatol 1992;128:1091-95.

22. Mehregan DR, Oursler JR, Leiferman KM, et al. Paraneoplastic pemphigus: A subset of patients with pemphigus and neoplasias. J Cut Pathol 1993;20:203-10.

23. Nguyen VT, Ndoye A, Bassler KD, et al. Classification, clinical manifestations, and immunological mechanisms of the epithelial variant of paraneoplastic autoimmune multiorgan syndrome: Reappraisal of paraneoplastic pemphigus. Arch Dermatol 2001; 137:193-206.

24. Liu AY, Valenzuela R, Helm TN, et al. Indirect immunofluorescence on rat bladder transitinal epithelium: A test with high specificity for paraneoplastic pemphigus. J Am Acad Dermatol 1993;28:696-99.

25. Camisa C, Helm TN, Valenzuela R, Korman NJ. Paraneoplastic pemphigus: Three new cases. J Invest Dermatol 1992;98:590 (abstract).

26. Mohan KH, Pai S, Rao R, Sripathi H, Prabhu S. Techniques of immunofluorescence and their significance. Indian $\mathrm{J}$ of Dermatol, Venereol and Leprol 2008; 74(4):415-19.

27. Mc Whirter JD, Hashimoto K, Fayne S, et al. Linear IgA bullous dermatosis related to lithium carbonate. Arch Dermatol 1987; 123:1120.

28. Van der Meer JB, Remme JJ, Nelkins MJJ, et al. IgA antibasement membrane antibodies in a boy with pemphigoid. Arch Dermatol 1977;113:1462.

29. Burrows NP, Bhogal BS, Black MM, et al. Bullous eruption of systemic lupus erthematosus: A clinicopathological study of four cases. Br J Dermatol 1993;128:332-38.

30. Gammon WR, Briggaman RA. Bullous SLE: A phenotypically distinctive but immunologically heterogeneous bullous disorder. J Invest Dermatol 1993;100:28-34.

31. Gammon WR, Wilson BD, Briggaman RA. Epidermolysis bullosa acquisita. In: Immunopathology of the skin (3rd ed). New York: Jhon Wiley \& Sons Inc 1987;383-97.

32. Chan PT. Cilinical features and diagnosis of common autoimmune bullous diseases. Hong Kong Medical Bulletin 2008 Oct; $13: 10$

\section{ABOUT THE AUTHORS}

\section{Roopa S Rao (Corresponding Author)}

Professor, Department of Oral Pathology, MS Ramaiah Dental College and Hospital, Bengaluru, Karnataka, India, e-mail: drroopasrao1971@ gmail.com

\section{BR Premalatha}

Senior Lecturer, Department of Oral Pathology, MS Ramaiah Dental College and Hospital, Bengaluru, Karnataka, India

\section{Vijaya Mysorekar}

Professor, Department of Pathology, MS Ramaiah Medical College and Hospital, Bengaluru, Karnataka, India

\section{Saurabh Juneja}

Postgraduate Student, Department of Oral Pathology, MS Ramaiah Dental College and Hospital, Bengaluru, Karnataka, India 